\title{
Production of reuterin in a fermented milk product by Lactobacillus reuteri: Inhibition of pathogens, spoilage microorganisms, and lactic acid bacteria
}

\author{
Y. Ortiz-Rivera, ${ }^{*}$ R. Sánchez-Vega, ${ }^{*}$ N. Gutiérrez-Méndez,† J. León-Félix,ł C. Acosta-Muñiz, ${ }^{*}$ \\ and D. R. Sepulveda*1 \\ ${ }^{*}$ Centro de Investigación en Alimentación y Desarrollo A.C., Unidad Cuauhtémoc, Av. Río Conchos S/N, Parque Industrial, Ciudad Cuauhtémoc, \\ Chihuahua, C.P. 31570, México \\ †Universidad Autónoma de Chihuahua, Facultad de Ciencias Químicas, Campus Universitario \#2, Circuito Universitario Chihuahua, C.P. 31125, \\ México \\ ¥Centro de Investigación en Alimentación y Desarrollo A.C., Unidad Culiacán, Carretera a El Dorado, Km 5.5, Campo el 10, Culiacán, Sinaloa, \\ C.P. 80129 , México
}

\begin{abstract}
We assessed the antimicrobial activity of reuterin produced in vitro in glycerol aqueous solutions in situ by Lactobacillus reuteri ATCC 53608 as part of a fermented milk product against starter (Lactobacillus delbrueckii ssp. bulgaricus and Streptococcus thermophilus), spoilage (Penicillium expansum), pathogenic (Staphylococcus aureus, Salmonella enterica ssp. enterica, and Listeria monocytogenes), and pathogen surrogate (Escherichia coli DH5 $\alpha$ ) microorganisms. We also assayed the influence of cold storage $\left(28 \mathrm{~d}\right.$ at $\left.4^{\circ} \mathrm{C}\right)$ and reuterin on the color and rheology of the fermented milk product. We obtained maximum reuterin concentrations of 107.5 and $33.97 \mathrm{mM}$ in glycerol aqueous solution and fermented milk product, respectively. Reuterin was stable throughout its refrigerated shelf life. Gram-positive microorganisms were more resistant to reuterin than gram-negative microorganisms. Penicillium expansum and Lactobacillus reuteri ATCC 53608 survived at concentrations up to 10 and $8.5 \mathrm{~m} M$, respectively. Escherichia coli DH5a was the most sensitive to reuterin $(0.9 \mathrm{mM})$. The presence of reuterin did not cause relevant changes in the quality parameters of the fermented milk product, including $\mathrm{pH}$, acidity, soluble solids, color, and rheological aspects (storage and loss moduli and viscosity). This study demonstrated the viability of using Lactobacillus reuteri ATCC 53608 as a biopreservative in a fermented milk product through reuterin synthesis, without drastically modifying its quality parameters.
\end{abstract}

Key words: reuterin, Lactobacillus reuteri, fermented milk product, biopreservation

Received May 30, 2016.

Accepted February 3, 2017.

${ }^{1}$ Corresponding author: dsepulveda@ciad.mx

\section{INTRODUCTION}

The most common method used to extend the shelf life of yogurt and fermented milks is refrigeration. The refrigerated shelf life of these products vary greatly depending on many factors, such as storage temperature (Birollo et al., 2000) and the presence of spoilage (Mataragas et al., 2011) or pathogenic microorganisms (O'Mahony et al., 1990; El-Sharoud, 2009). Important outbreaks of foodborne diseases caused by Escherichia coli, Staphylococcus aureus, Salmonella spp., and Listeria spp. in dairy products have been reported in recent years (Morgan et al., 1993; Gulmez and Guven, 2003; Braden and Tauxe, 2013; Bianchi et al., 2014; Kemal, 2014). Benzoic and sorbic acids, as well as their salts, are typically employed as preservatives in dairy products to avoid the growth of unwanted microorganisms (Mroueh et al., 2008). However, consumers are increasingly demanding a reduction in the use of synthetic chemical agents for food preservation (Mills et al., 2011), and alternative strategies to extend the shelf life of foods have been proposed. Of special interest are those based on the use of natural substances (Gyawali and Ibrahim, 2014). Lactic acid bacteria may be successfully used as a biopreservation strategy and a substitute for artificial preservatives. The use of lactic acid bacteria takes advantage of the capacity of some strains to synthetize chemical compounds such as alcohols, organic acids, carbon dioxide, diacetyl, hydrogen peroxide, and other substances that are capable of inhibiting the growth of unwanted microorganisms (Helander et al., 1997).

An example of this strategy is the use of Lactobacillus reuteri. Some strains of $L b$. reuteri can synthesize reuterin (3-hydroxypropionaldehyde), a broad-spectrum antimicrobial agent produced during the anaerobic metabolism of glycerol (Talarico et al., 1988). Reuterin has potent antimicrobial effects against bacteria, yeast, fungi, and protozoa (Talarico et al., 1988; Axelsson et al., 1989; Chung et al., 1989; Talarico and Dobrogosz, 
1989). The use of reuterin to prevent the growth of spoilage and pathogenic microorganisms in dairy products has been evaluated (el-Ziney and Debevere, 1998; Langa et al., 2013). Arqués et al. (2004) reported that 8 $\mathrm{AU} / \mathrm{mL}$ of reuterin in milk caused bacteriostatic activity against Listeria monocytogenes and bactericidal effects against Staph. aureus, E. coli O157:H7, Salmonella choleraesuis ssp. choleraesuis, Yersinia enterocolitica, Aeromonas hydrophila ssp. hydrophila, and Campylobacter jejuni. Several other studies have demonstrated the effectiveness of reuterin as an antimicrobial agent (Axelsson et al., 1989; Chung et al., 1989; Rasch, 2002; Cleusix et al., 2007; Spinler et al., 2008; Garde et al., 2014). However, the synthesis and accumulation of reuterin in situ through the activity of $L b$. reuteri in preserved food has not been explored as fully, probably due to the technical difficulties involved in achieving the conditions required for reuterin synthesis in food products without drastically modifying their quality traits. Still, the use of $L b$. reuteri as a biopreservative is very relevant from a commercial point of view, because in situ production of reuterin allows for clean labeling. The ability of $L b$. reuteri to synthesize reuterin is strongly dependent on temperature, $\mathrm{pH}$, oxygen concentration, cell age, and biomass (Lüthi-Peng et al., 2002b); developing a food manufacture process in which $L b$. reuteri survives and synthesizes reuterin is a challenge.

Langa et al. (2013) explored in situ reuterin production in a yogurt model system, in which $L b$. reuteri survived to produce reuterin. Nevertheless, the maximum reuterin concentration achieved in that study reached only $1.5 \mathrm{~m} M$, which may not be enough to effectively protect against microbial development over a product's shelf life. The purpose of this research was to produce a fermented milk product in which live $L b$. reuteri ATCC 53608 synthesized reuterin at higher levels and to evaluate the antimicrobial effect of reuterin on pathogens, starter cultures, spoilage microorganisms, and $L b$. reuteri itself, throughout the refrigerated shelf life of the fermented milk product.

\section{MATERIALS AND METHODS}

\section{Materials and Strains}

We purchased tryptophan; acrolein; USP-grade glycerol; ethanol; gentamicin sulfate; de Man, Rogosa and Sharpe (MRS) agar; MRS broth; tryptic soy broth; tryptic soy agar; reinforced clostridial agar; and potato glucose agar from Aldrich Chemical Co. (St. Louis, MO). Sodium chloride and dibasic sodium phosphate anhydrous were supplied by Fermont (Productos Químicos Monterrey, S.A. de C.V., NL, México). We purchased M17 agar, sodium hydroxide, and hydrochloric acid from Dibico S.A. de C.V. (México, México), Alfa Aesar (Haverhill, MA), and Mallinckrodt Baker (Austin, TX), respectively.

We obtained food pathogen microorganisms Staph. aureus, Salmonella enterica ssp. enterica (S. enterica), L. monocytogenes wild type, and E. coli DH5a (studied as a pathogen surrogate) isolated from food, as well as spoilage fungus Penicillium expansum, from the Centro de Investigación en Alimentación y Desarrollo, A.C., culture collection (Ciudad Cuauhtémoc, México). We purchased $L b$. reuteri ATCC 53608 from IECSA (México, México). We purchased starter culture (Lactobacillus delbrueckii ssp. bulgaricus, hereinafter called Lb. delbrueckii, and Streptococcus thermophilus) from Chr. Hansen (Hørsholm, Denmark).

\section{Methods}

Reuterin was first bio-synthesized in vitro and purified to characterize $L b$. reuteri ATCC 53608's synthesis capacity, and to test the in vitro susceptibility to reuterin of all involved microorganisms. Once this was accomplished, we developed a fermented milk manufacturing method that allowed for in situ reuterin production. To test the effectiveness of this method as a bio-preservation strategy, a post-process contamination was simulated, inoculating pathogen and spoilage microorganisms before studying the fermented milk product throughout its refrigerated shelf life, focusing on microbial populations and quality attributes (color and consistency).

In Vitro Lb. reuteri Biomass and Reuterin Production. Reuterin production was achieved following a 2-step process described by Doleyres et al. (2005). Stock frozen culture of $L b$. reuteri strain ATCC 53608 was inoculated at $1 \%$ in MRS broth and incubated at $37^{\circ} \mathrm{C}$ for $15 \mathrm{~h}$. This overnight culture was transferred at $1 \%$ into MRS broth with $20 \mathrm{~m} \mathrm{M}$ glycerol and incubated at $37^{\circ} \mathrm{C}$ under anaerobic conditions for $15 \mathrm{~h}$, maintaining the $\mathrm{pH}$ at 5.5 using $5 \mathrm{M} \mathrm{NaOH}$. Cells were harvested after incubation (Incubator VWR International, Radnor, PA) by centrifugation at $1,500 \times g$ for 10 min at $20^{\circ} \mathrm{C}$ (centrifuge $5430 \mathrm{R}$; Eppendorf, Hamburg, Germany) and washed twice with $0.1 M$ potassium phosphate buffer, $\mathrm{pH}$ 7. Pellets from the preceding step were suspended in $200 \mathrm{~m} M$ glycerol solution and incubated at $37^{\circ} \mathrm{C}$ for $120 \mathrm{~min}$. For reuterin isolation, the cell suspension was centrifuged at $12,000 \times g$ for 20 min at $4^{\circ} \mathrm{C}$. The supernatant was recovered and filtered $(0.2 \mu \mathrm{m}$; Corning Inc., Corning, NY). The filtrate was considered the reuterin aqueous extract.

Reuterin Quantification. Reuterin quantification in aqueous solutions and in the fermented milk product 
was carried out following the colorimetric method proposed by Circle et al. (1945), with some modifications. Briefly, $330 \mu \mathrm{L}$ of filtered solution were mixed with 75 $\mu \mathrm{L}$ of $0.1 \mathrm{M}$ tryptophan (dissolved in $0.05 \mathrm{~N} \mathrm{HCl}$ ) and $150 \mu \mathrm{L}$ of $95 \%$ ethanol. This mixture was incubated at $40^{\circ} \mathrm{C}$ for $50 \mathrm{~min}$ and the absorbance was read at $560 \mathrm{~nm}$ (Spectrophotometer Evolution 201; Thermo Scientific, Waltham, MA). A curve of acrolein was constructed in the range of 15 to $150 \mu \mathrm{g} / \mathrm{mL}$, and the reuterin concentration was calculated by comparing the absorbance of the samples with a calibration curve built with acrolein, assuming that $1 \mathrm{~mol}$ of reuterin was dehydrated to $1 \mathrm{~mol}$ of acrolein that reacted with tryptophan in the presence of $\mathrm{HCl}$. The analytic detection limit was set at $15 \mu \mathrm{g} / \mathrm{mL}$, because it was the lowest concentration of the employed calibration curve. Reuterin concentration was measured in the aqueous extracts when necessary and weekly throughout the shelf-life study in the fermented milk product.

Reuterin In Vitro Inhibition Tests. Pathogen microorganisms were cultured in tryptic soy broth and incubated at $37^{\circ} \mathrm{C}$ for $24 \mathrm{~h}$ under aerobic conditions. Starter cultures and Lb. reuteri ATCC 53608 were cultured in MRS broth. Anaerobic conditions were applied only for Lactobacillus microorganisms. Anaerobic incubation was accomplished in jars with an $\mathrm{H}_{2}$ plus $\mathrm{CO}_{2}$ generating kit (AnaeroGen; Oxoid, Basingstoke, UK). Tryptic soy agar was used for pathogen microorganisms plate counts, which were cultured at $37^{\circ} \mathrm{C}$ for 24 h. We incubated Lb. delbrueckii, Strep. thermophilus, and $L b$. reuteri ATCC 53608 under the same conditions and counted in reinforced clostridial agar $\mathrm{pH}$ 5.3, M17, and MRS agar, respectively. Penicillium expansum was cultured on potato glucose agar and incubated at $28^{\circ} \mathrm{C}$ for $3 \mathrm{~d}$.

We evaluated the susceptibility of microorganisms to reuterin following the method described by Arqués et al. (2004). An overnight culture of pathogenic bacteria (E. coli DH5 $\mathrm{\alpha}$, L. monocytogenes, Staph. aureus, and $S$. enterica), starter cultures ( $L b$. delbrueckii and Strep. thermophilus), and Lb. reuteri ATCC 53608 were washed twice with $0.05 M$ sodium phosphate buffer, $\mathrm{pH} 7.5$, and suspended in this buffer to reach an optical density of 0.6 at $595 \mathrm{~nm}$. This suspension was diluted to $1: 10$ in tryptic soy broth, $0.5 \mathrm{~mL}$ of the cell suspension was transferred to $4.5 \mathrm{~mL}$ of tryptic soy broth, and then $150 \mu \mathrm{L}$ of reuterin solutions at different concentrations and $150 \mu \mathrm{L}$ of the 1:10 suspension were mixed. Microplates containing the mixture of reuterin and microorganisms were incubated at $37^{\circ} \mathrm{C}$ for $24 \mathrm{~h}$. After this time, each suspension was cultured in agar using the spread plate technique for microbiological count determination. Wells with $150 \mu \mathrm{L}$ of $200 \mathrm{mM}$ glycerol solution and $150 \mu \mathrm{L}$ of each tested strain were used as positive controls of growth without inhibitory activity of reuterin.

In the case of spoilage fungi ( $P$. expansum), the reuterin susceptibility test was performed in potato dextrose agar prepared at different reuterin concentrations $(0,3,6,9,12,15,18$, and $21 \mathrm{mM})$. Fungus was inoculated using the spread plate technique and incubated at $28^{\circ} \mathrm{C}$. The MIC was the minimal reuterin concentration at which growth was not observed after $5 \mathrm{~d}$ of incubation.

Manufacture of the Fermented Milk Product and Reuterin Production In Situ. Preparation of fermented milk product was based on the methodology described by Hekmat et al. (2009). Pasteurized (HTST) skim milk (Zaragoza Light, Chihuahua, México) containing $1 \%$ fat and $5 \%$ carbohydrates was heated at $87^{\circ} \mathrm{C}$ for $30 \mathrm{~min}$ and cooled to $40^{\circ} \mathrm{C}$. The milk was then inoculated with $0.2 \%$ freeze-dried starter cultures (Chr. Hansen, Hørsholm, Denmark): Lb. delbrueckii and Strep. thermophilus. The milk was then transferred to polystyrene screw-cap tubes with Lb. reuteri ATCC 53608 in pellet form and homogenized to obtain an initial concentration of $5.1 \times 10^{9}$ $\mathrm{cfu} / \mathrm{mL}$. Reuterin synthesis was promoted by adding $200 \mathrm{mM}$ glycerol USP to the fermented milk product during fermentation. The glycerol was added to the milk $4 \mathrm{~h}$ after inoculation to avoid reuterin interfering with the acidifying action of the lactobacilli. At this point, the $\mathrm{pH}$ was between 5 and 5.5. We used fermented milk product with $L b$. reuteri ATCC 53608 but without glycerol as a negative control for reuterin production. Addition and homogenization of glycerol $4 \mathrm{~h}$ after the onset of fermentation produced a stirred-type fermented milk product. The temperature was held at $40^{\circ} \mathrm{C}$, and lactic acid production was monitored using a pH meter (Hanna HI 2210, Hanna Instruments, Woonsocket, RI), until the product reached a final $\mathrm{pH}$ of 4.5. At the end of fermentation, pathogen and spoilage microorganisms were added and homogenized $\left(10^{8}\right.$ to $\left.10^{9} \mathrm{cfu} / \mathrm{mL}\right)$ to simulate post-process contamination. The fermented milk product was cooled at $4^{\circ} \mathrm{C}$ and stored at this temperature for analysis throughout the shelf-life studies $(28 \mathrm{~d})$. Preliminary studies demonstrated that the addition of $L b$. reuteri ATCC 53608 or glycerol by themselves did not influence the capacity of starter microorganisms to ferment milk; this was confirmed by the fact that the curve of milk acidification remained unchanged.

Proximate Analysis of the Fermented Milk Product. Humidity, ash, protein, and fat content were quantified by gravimetric methods (934.01 and 945.46), the Kjeldahl method (method 991.2 AOAC), and the 
modified Mojonnier ether extraction method (method 989.05), respectively (AOAC International, 2002).

Packaging and Storage of the Fermented Milk Product. The fermented milk product was stored in sterile 50-mL polystyrene screw-cap tubes during the refrigerated shelf-life studies. Once filled, each container was tightly closed and stored under refrigeration at $4^{\circ} \mathrm{C}$, until analysis. Fermented milk product samples were taken at $1,7,14,21$, and $28 \mathrm{~d}$.

Inhibitory Activity of Reuterin in Fermented Milk. Pathogen microorganisms were separately inoculated into the prepared fermented milk product. An overnight culture of each microorganism was washed twice with $0.05 \mathrm{M}$ sodium phosphate buffer, $\mathrm{pH} 7.5$, and suspended in this buffer to achieve an optical density of 0.6 at $595 \mathrm{~nm}$. This suspension was diluted to 1:10 in tryptic soy broth, $0.5 \mathrm{~mL}$ of the cell suspension was transferred to $4.5 \mathrm{~mL}$ of fermented milk product, and the product was thoroughly mixed and stored at $4^{\circ} \mathrm{C}$. We tested the levels of contamination using the plate extension technique at the moment of inoculation and every $5 \mathrm{~h}$ until $21 \mathrm{~h}$ after contamination. Samples were monitored every $7 \mathrm{~d}$ afterward. We used fermented milk product without glycerol and inoculated with each pathogen as positive controls of growth, as proposed by Arqués et al. (2004) and Gulmez and Guven (2003). We monitored the survival of starter microorganisms and Lb. reuteri ATCC 53608 in a similar way.

\section{Quality Analyses}

Rheological Analysis. We carried out rheological analyses on $\mathrm{d} 1,7,14,21$, and 28 of storage at $4^{\circ} \mathrm{C}$ using a controlled-stress rheometer (AR 1500ex; TA Instruments, New Castle, DE). Storage $\left(\mathbf{G}^{\prime}\right)$ and loss $\left(\mathbf{G}^{\prime \prime}\right)$ modulus $(\mathrm{Pa})$, as well as apparent viscosity $(\mathrm{Pa} \cdot \mathrm{s})$ were determined at controlled temperature $\left(5^{\circ} \mathrm{C} \pm 0.5\right)$. Tests were carried out with maximum deformation of $1 \%$ and the frequency varied between 0.01 and $10 \mathrm{~Hz}$ (Cruz et al., 2013). We registered $\mathrm{G}^{\prime}, \mathrm{G}^{\prime \prime}$, and viscosity values at a frequency of $10 \mathrm{~Hz}$, where the crossover point between $\mathrm{G}^{\prime}$ and $\mathrm{G}^{\prime \prime}$ took place.

Color, pH, Acidity, and Soluble Solids Analyses. The color of fermented milk products was measured using a Colorimeter (Minolta CR-300, Konica Minolta Sensing, Inc., Osaka, Japan) at room temperature. The CIE $L^{*}$ (lightness), $\mathrm{a}^{*}$ (red-green color), and $\mathrm{b}^{*}$ (yellow-blue color) coordinates were determined. The $\mathrm{pH}$ value was measured using a $\mathrm{pH}$ meter $(\mathrm{pH}$ meter HI 2210, Hanna Instruments) at the end of the fermentation, after $12 \mathrm{~h}$, and weekly for $28 \mathrm{~d}$ of storage

Acidity was calculated as lactic acid percent at the end of the fermentation process. An aliquot $(1 \mathrm{~mL})$ of fermented milk product was diluted in $9 \mathrm{~mL}$ of distilled water and titrated against $0.1 M$ sodium hydroxide and $1 \%$ phenolphthalein diluted in ethanol as indicator of the end point (Gonzalez et al., 2011).

Soluble solids were determined using a refractometer (Atago RX-1000, Atago Company Ltd., Tokyo, Japan) and expressed as ${ }^{\circ}$ Brix.

\section{Statistical Analyses}

Statistical analyses were conducted using a one-way ANOVA to evaluate the influence of reuterin over quality parameters during shelf life at each sampling time. Analyses of variance was conducted using SAS software (SAS Institute Inc., Cary, NC) and significant differences among means were established at $\alpha=0.05$ using Tukey's test. All experiments were conducted in triplicate.

\section{RESULTS AND DISCUSSION}

\section{Fermented Milk Product Characterization}

The composition of the fermented milk product is shown in Table 1. The fermented milk product manufactured in the present study complied with the specifications and standards for yogurt of the Codex Alimentarius Commission (FAO, 2011); however, dairy products with no living lactic acid bacteria, such as the ones obtained in this study, can only be considered fermented milk products (Yildiz, 2010).

The quality parameters (color, $\mathrm{pH}$, and acidity) of the fermented milk products without reuterin also aligned with the values reported in literature for yogurt (Cruz et al., 2010; FAO, 2011). The reuterin-free products complied with the presence of live bacteria as well.

\section{Reuterin Production in Aqueous Glycerol Solution and Fermented Milk Product}

Reuterin production by $L b$. reuteri ATCC 53608 in glycerol solutions was $107.5 \pm 11.22 \mathrm{~m} M$ under the con-

Table 1. Proximate analysis and characterization of fermented milk product $^{1}$

\begin{tabular}{lc}
\hline Item & Fermented milk product \\
\hline Protein (\%) & $3.39 \pm 0.36$ \\
Fat (\%) & $1.73 \pm 0.15$ \\
Ash (\%) & $0.70 \pm 0.01$ \\
Carbohydrates (\%) & $5.32 \pm 0.18$ \\
Starter culture (cfu/mL) & $8.4 \times 10^{9}$ \\
Lactobacillus delbrueckii & $8.9 \times 10^{5}$ \\
Streptococcus thermophilus & \\
\hline
\end{tabular}

${ }^{1}$ Values are the mean of 3 replicates \pm SD. 
ditions employed in this study. Other research groups have reported values in the range of 45.7 to $298 \mathrm{mM}$ under similar conditions (Cleusix et al., 2007; Tobajas et al., 2007; Spinler et al., 2008). Differences in the amount of synthesized reuterin found in this study and others may be caused by the use of different $L b$. reuteri strains (Spinler et al., 2008), as well as by culture factors such as temperature, $\mathrm{pH}$, biomass concentration, medium composition, oxygen concentration, cell age, length of incubation, and the presence of heterologous cells (Lüthi-Peng et al., 2002a,b; Doleyres et al., 2005; Bauer et al., 2010).

Reuterin synthesis by Lb. reuteri ATCC 53608 in fermented milk product reached a maximum value of 33.97 $\pm 4.90 \mathrm{~m} M$. This reuterin concentration represented an improvement over previously reported efforts, in which a maximum concentration of $1.73 \mathrm{mM}$ was achieved with the activity of $L b$. reuteri ATCC 53608 in yogurt. Because the objective of this study was to increase reuterin production, we conducted shelf-life studies using this high concentration to determine its potential effect on the quality characteristics of the product. A lower concentration may be sufficient for preservation purposes and would probably allow for the survival of lactic acid bacteria.

Other dairy products such as cheese have been tested as media for reuterin production, achieving maximum concentrations of $5.7 \mathrm{mM}$, also lower than the level reached in this study (Langa et al., 2013).

Reuterin produced in the fermented milk product was stable throughout the shelf-life studies (28 d at $4^{\circ} \mathrm{C}$ ), ranging in concentrations from 28.33 to 31.22 $\mathrm{m} M$ with no statistically significant differences among them. Vollenweider et al. (2003) reported that purified reuterin could be stored for at least 6 mo at refrigeration temperature $\left(4^{\circ} \mathrm{C}\right)$ without loss or transformation. In this regard, milk products containing reuterin and stored at $4^{\circ} \mathrm{C}$ may be considered innocuous, because no acrolein conversion is expected under these conditions (el-Ziney and Debevere, 1998; Vollenweider et al., 2003). In a similar way, Langa et al. (2013) reported a minimal reduction of $0.38 \mathrm{~m} M$ in the concentration of reuterin in yogurt after $28 \mathrm{~d}$ of refrigerated storage. It may be concluded that the antimicrobial activity of reuterin in the fermented milk product remains stable during refrigerated shelf life.

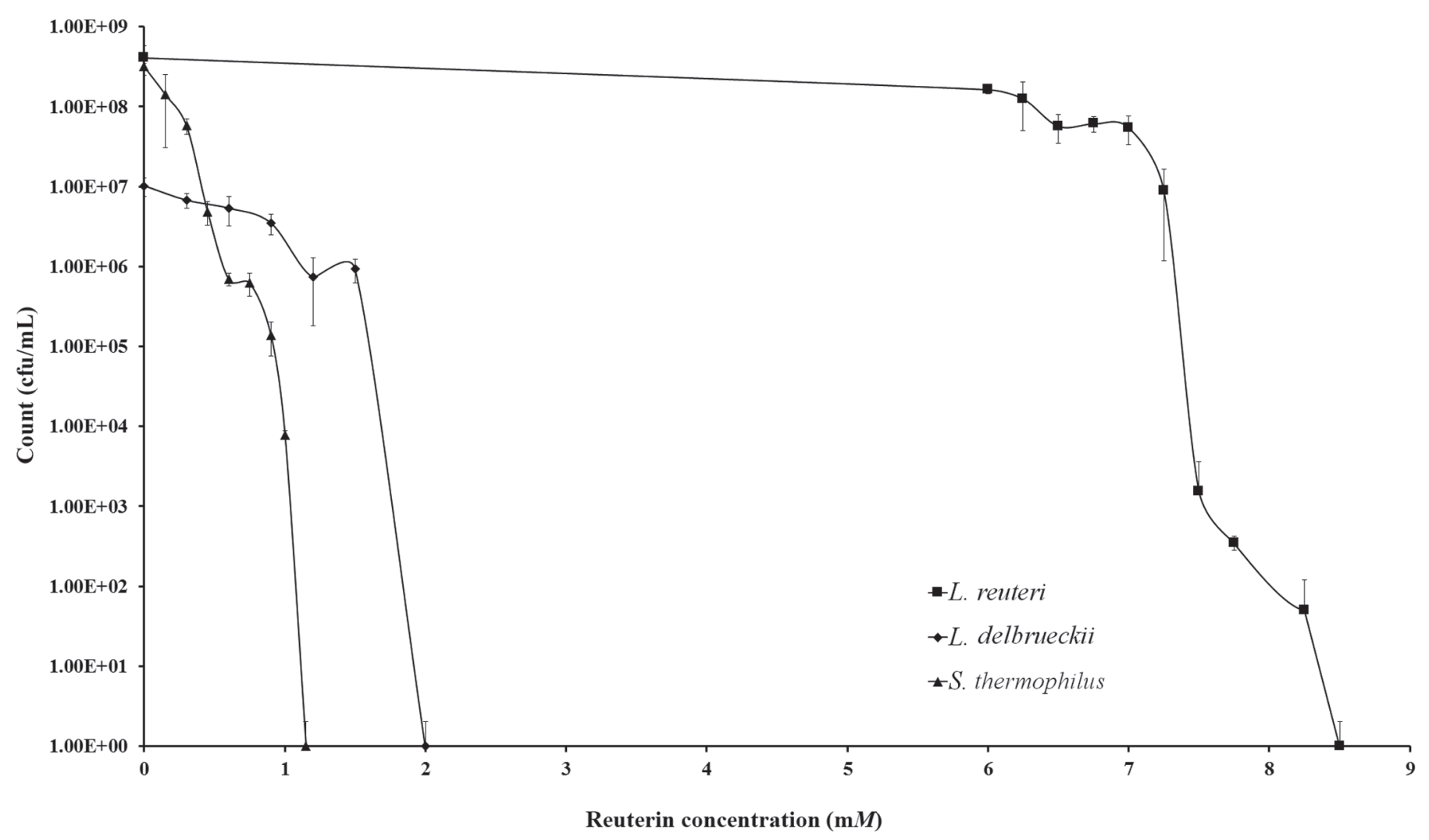

Figure 1. Curve of starter culture (Lactobacillus delbrueckii and Streptococcus thermophilus) and Lactobacillus reuteri ATCC 53608 inhibition by reuterin. Error bars represent 1 SD. 


\section{Effect of Reuterin Concentration on Inhibition of Starter Culture, Pathogen, and Spoilage Microorganisms in Glycerol Solutions}

We assayed the susceptibility of $L b$. reuteri ATCC 53608, Lb. delbrueckii, and Strep. thermophilus to reuterin in glycerol solutions and found that $L b$. reuteri ATCC 53608 showed the highest resistance to reuterin, inhibited at concentrations of $8.5 \mathrm{~m} M$ reuterin and higher, but that Lb. delbrueckii $(2 \mathrm{mM})$ and Strep. thermophilus $(1.2 \mathrm{mM})$ were more susceptible to reuterin inhibition (Figure 1). Similarly, Cleusix et al. (2007) demonstrated that $L b$. reuteri was the most resistant to reuterin inhibition compared with other Lactobacillus species. Nevertheless, these authors reported that higher reuterin concentrations (30 to $50 \mathrm{~m} M$ ) were necessary to reach the MIC for $L b$. reuteri, in contrast with the results observed in the present study. These differences in susceptibility were most probably related to the study of different strains and different environmental conditions. A notable difference in reuterin susceptibility among strains has been reported in other lactobacilli. Chung et al. (1989) reported inhibition of Lactobacillus acidophilus of 2.6 to $8.65 \mathrm{~m} M$ reuterin, whereas Cleusix et al. (2007) reported inhibition of the same microorganisms at reuterin concentrations of 15 to $40 \mathrm{mM}$.

We did not detect Staph. aureus, E. coli DH5a, L. monocytogenes, or $S$. enterica after incubation (24 $\mathrm{h}$ at $37^{\circ} \mathrm{C}$ ) in reuterin aqueous solutions (Figure 2). The most resistant pathogen was Staph. aureus, showing resistance up to $1.5 \mathrm{~m} M$ reuterin. In contrast, the most reuterin-susceptible microorganism was E. coli DH5 $\alpha$, which was inhibited at the lowest concentration of reuterin $(0.9 \mathrm{mM})$, in accordance with the findings of Lüthi-Peng et al. (2002b), who reported that low concentrations of reuterin $(0.1 \mathrm{mM})$ were enough to reach the MIC for E. coli DH5 $\alpha$. However, as with the susceptibility of lactobacilli, the literature also reports great variation in the susceptibility of pathogens to reuterin, probably because of strain differences. Cleusix et al. (2007) reported MIC in the range of 15 to $30 \mathrm{mM}$ for E. coli, and Spinler et al. (2008) demonstrated that concentrations of $10 \mathrm{~m} M$ of reuterin caused up to $95 \%$ growth inhibition of S. enterica, E. coli, Shigella sonnei, and Vibrio cholera.

In general, gram-negative bacteria (E. coli $\mathrm{DH} 5 \alpha$ and $S$. enterica) showed greater susceptibility to reuterin than gram-positive bacteria ( $L$. monocytogenes and Staph. aureus; Figure 2). In agreement with the find-

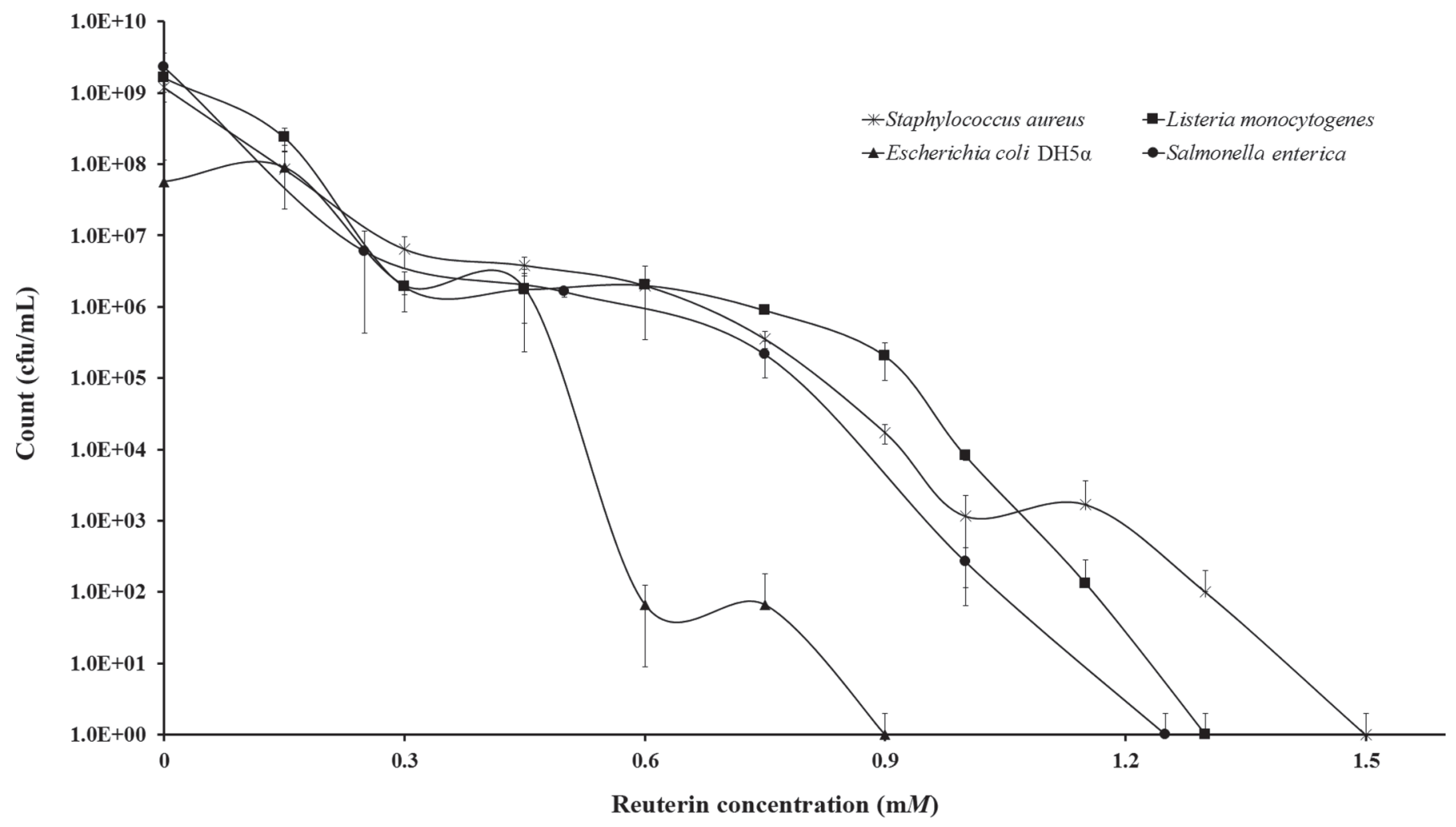

Figure 2. Curve of pathogen inhibition by reuterin. Error bars represent 1 SD. 
ings of this study, Arqués et al. (2004) demonstrated that gram-positive pathogens Staph. aureus and $L$. monocytogenes were more resistant to reuterin than gram-negative E. coli $\mathrm{DH} 5 \alpha$ and $Y$. enterocolitica. The exact inhibiting mechanism of reuterin over microorganisms is still unknown; however, some theories have been postulated. Vollenweider and Lacroix (2004) proposed that hydroxyl and aldehyde groups in reuterin might react with sulfhydryl groups of ribonucleotide reductase and thioredoxin, inactivating proteins and molecules containing these groups. Another theory proposed by Talarico and Dobrogosz (1989) states that reuterin is structurally similar to ribose, leading to the impairment of DNA synthesis through competition with ribonucleotides for binding opportunities with the ribose recognition site. More insight into the inactivation mechanisms of reuterin would greatly expand the potential as a preservation principle in food technology.

In the case of a spoilage microorganism ( $P$. expansum), the concentration at which mold growth was completely inhibited corresponded to $10 \pm 1.73 \mathrm{mM}$ (after $24 \mathrm{~h}$ of incubation). Chung et al. (1989) observed that $2.7,1.8$, and $8.1 \mathrm{mM}$ reuterin were necessary to achieve a MIC for Saccharomyces cerevisiae, Aspergillus flavus, and Fusarium samfucienum, respectively.

The studied microorganisms in order of reuterin susceptibility, starting from the most resistant, were P. expansum, Lb. reuteri ATCC 53608, Lb. delbrueckii, Staph. aureus, L. monocytogenes, S. enterica, Strep. thermophilus, and E. coli DH5a. Likewise, Chung et al. (1989) demonstrated that bacteria were notably more susceptible to reuterin than yeasts and molds.

\section{Survival of Microorganisms in the Fermented Milk Product Containing Reuterin}

The survival of $L b$. reuteri ATCC 53608, Lb. delbrueckii, and Strep. thermophilus in fermented milks with and without reuterin is shown in Figure 3. The Lb. reuteri ATCC 53608, Lb. delbrueckii, and Strep. thermophilus initial counts were $4.1 \times 10^{9}, 8.4 \times 10^{9}$ and $1 \times 10^{8} \mathrm{cfu} / \mathrm{mL}$, respectively. However, the total counts of $L b$. reuteri ATCC 53608, Lb. delbrueckii, and Strep. thermophilus reached a steady value between 3.0 $\times 10^{9}$ and $4.1 \times 10^{9} \mathrm{cfu} / \mathrm{mL}$ after $5 \mathrm{~h}$ of fermentation in

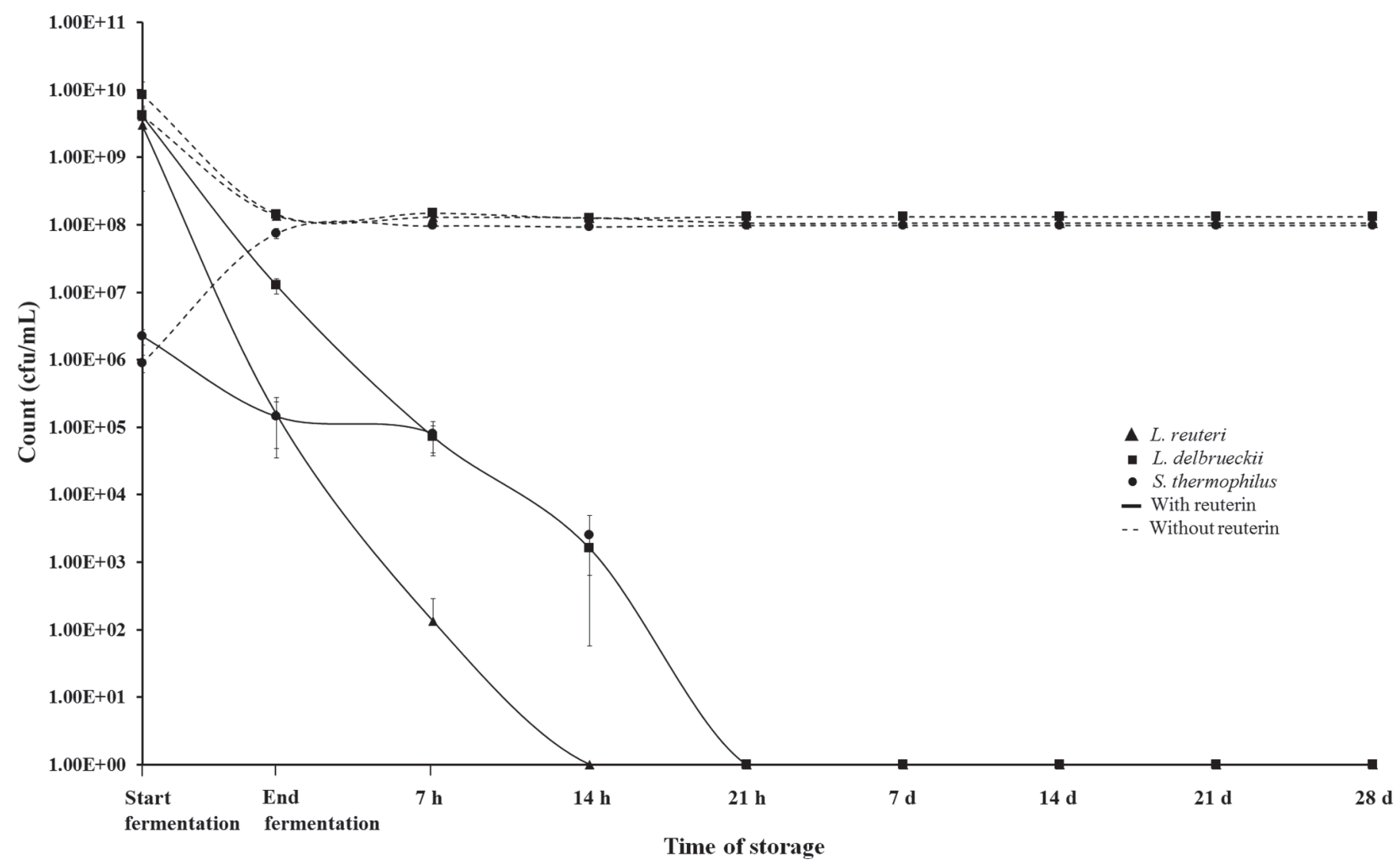

Figure 3. Survival of starter culture (Lactobacillus delbrueckii and Streptococcus thermophilus) and Lactobacillus reuteri ATCC 53608 in fermented milk product with and without reuterin. Error bars represent $1 \mathrm{SD}$. 
reuterin-free fermented milk product. This population adjustment was most probably related to an increase in the acidity of the fermented milk product and to the initial presence of oxygen (Donkor et al., 2007; Hekmat et al., 2009). After 5 h, both $L b$. reuteri ATCC 53608 and the starter culture remained stable throughout the storage time $\left(10^{8} \mathrm{cfu} / \mathrm{mL}\right)$ in reuterin-free fermented milk products (Figure 3). In contrast, we did not detect growth of $L b$. reuteri ATCC 53608 or starter culture after $21 \mathrm{~h}$ of storage in the fermented milk product containing reuterin $(33.97 \pm 4.90 \mathrm{mM})$. We found no $L b$. reuteri ATCC 53608 live cells after $14 \mathrm{~h}$ of exposition to reuterin in the fermented milk product. Similarly, $L b$. delbrueckii, and Strep. thermophilus were completely inactivated after $21 \mathrm{~h}$. In contrast, a previous study of in situ reuterin production in yogurt reported the viability of starter cultures (Strep. thermophilus and $L b$. delbrueckii) and $L b$. reuteri ATCC 53608 after $28 \mathrm{~d}$ of storage (Langa et al., 2013). Nevertheless, the reuterin concentration employed in that study $(1.73 \mathrm{mM})$ was less than the concentration used in the present study, explaining the survival of these microorganisms.

Figure 4 shows the influence of reuterin on pathogen and spoilage microorganisms in fermented milk, comparing their survival with that of the same microorgan- isms in reuterin-free fermented milk product. Pathogen and spoilage microorganisms maintained a constant population level during the study in the reuterin-free fermented milk product. This observation shows that normal fermented milk product conditions (e.g., pH, osmotic pressure, nutrient concentration) allow for the survival of these microorganisms. In contrast, reuterin-containing fermented milk product $(33.97 \mathrm{mM})$ completely inhibited pathogen microorganisms E. coli DH5a, S. enterica, L. monocytogenes, and Staph. aure$u s$, as well as the spoilage microorganism $P$. expansum after $20 \mathrm{~h}$ of exposition. In the case of the fermented milk product, Staph. aureus, and S. enterica were more resistant to reuterin than E. coli $\mathrm{DH} 5 \alpha$ and L. monocytogenes, requiring 5 additional hours to reach complete inactivation. Gram-positive and gram-negative bacteria showed clearly differentiated susceptibility to reuterin in aqueous solutions, but this was not the case in the fermented milk product. Previous studies in milk (Arqués et al., 2007) found lower inactivation levels for $E$. coli and $Y$. enterocolitica (0.78 and $0.59 \log$ cycle reductions, respectively). However, these results were to be expected, because the reuterin concentration levels used were very low $(1.8 \mathrm{mM})$ compared with the ones used in the present study.

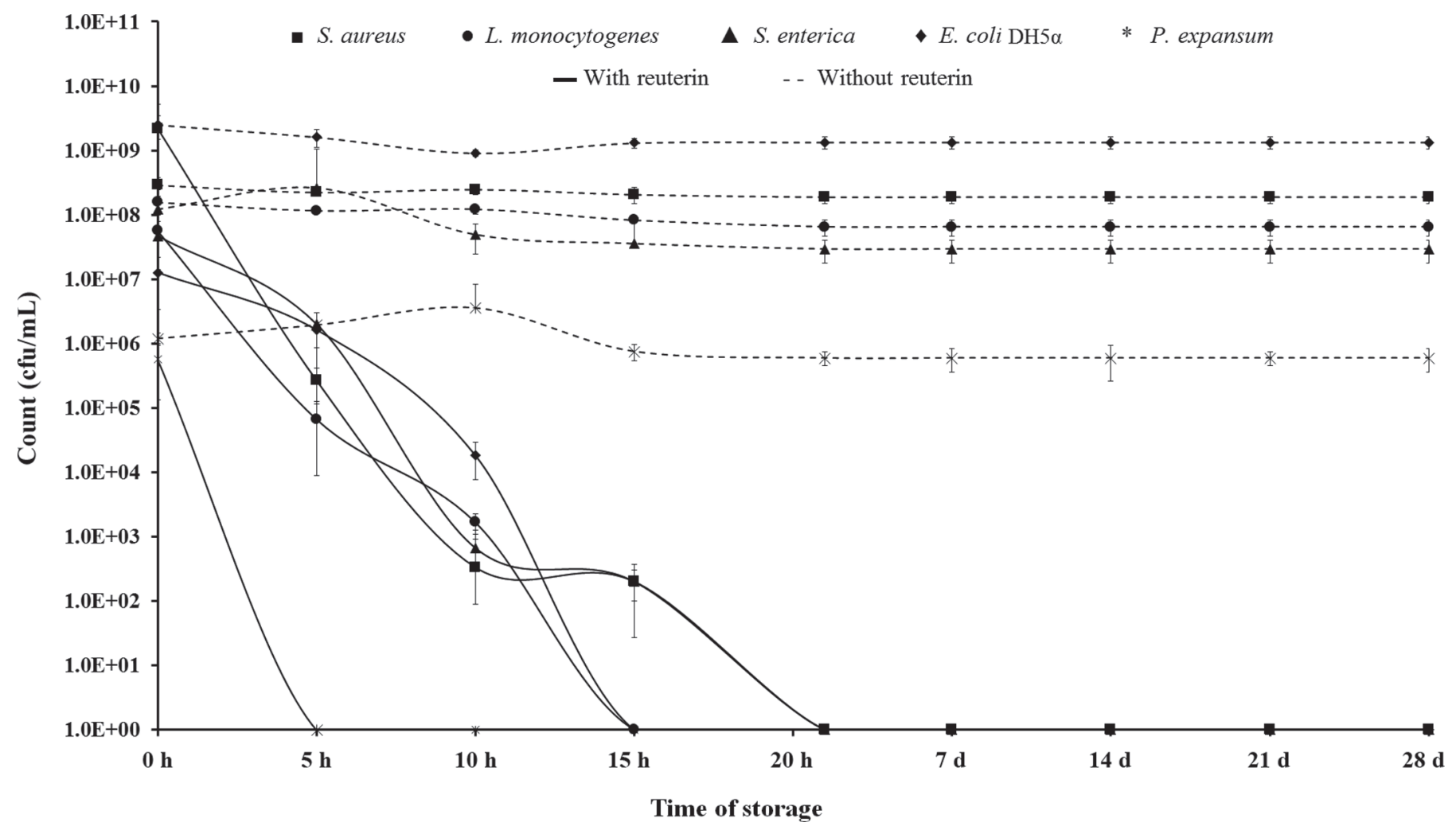

Figure 4. Survival of spoilage (Penicillium expansum) and pathogenic (Escherichia coli DH5a, Listeria monocytogenes, Staphylococcus aureus, and Salmonella enterica) microorganisms in fermented milk product. Error bars represent 1 SD. 


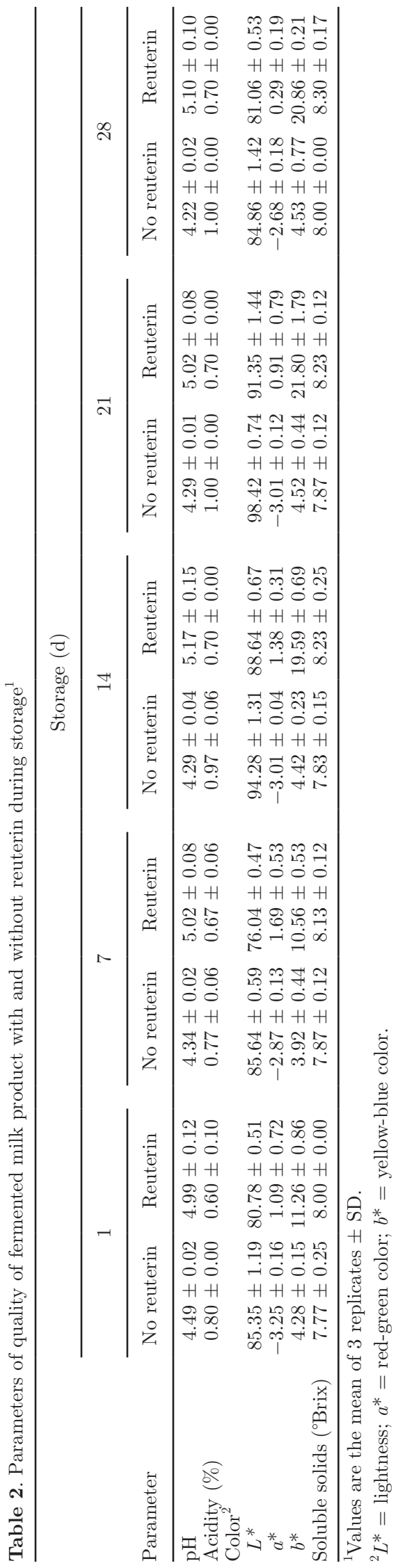

\section{Influence of Reuterin and Storage Time on Fermented Milk Product Quality}

Quality parameter values for the fermented milk product with and without reuterin during refrigerated storage are shown in Table 2. The $\mathrm{pH}$ (4.49), titratable acidity $(0.80 \%)$, and chemical composition of the fermented milk product without reuterin were within the range reported in literature at the beginning of the storage period (Cruz et al., 2010).

Acidity and $\mathrm{pH}$ are among the most important quality parameters for fermented milk products. In the present study, these parameters went without significant change throughout refrigeration storage $\left(28 \mathrm{~d}\right.$ at $\left.4^{\circ} \mathrm{C}\right)$ for fermented milk product with and without reuterin (Table 2). Similarly, Mataragas et al. (2011) reported that the $\mathrm{pH}$ and acidity of yogurt preserved under refrigeration temperatures $\left(5^{\circ} \mathrm{C}\right)$ remained almost constant through its shelf life. In contrast, Cruz et al. (2010) reported that yogurt $\mathrm{pH}$ decreased from 4.58 to 4.12 , and that the concentration of organic acids (lactic and acetic acids) increased (from 3.6 and 2.1 to 12.3 and $10.6 \mathrm{~g} / \mathrm{L}$, respectively) after $84 \mathrm{~d}$ of storage at $10^{\circ} \mathrm{C}$. Both the long storage period and the elevated storage temperature may have been responsible for the changes observed in pH and acidity by Cruz et al. (2010) compared with the present study. On the other hand, reuterin-free fermented milk product showed a significantly lower $\mathrm{pH}$ and a higher acidity value than the reuterin-containing fermented milk product throughout its shelf life. These results suggest that although active starter lactobacilli in the reuterin-free fermented milk product continued to ferment during the manufacturing process, the presence of reuterin inhibited this additional fermentation in the fermented milk product with reuterin.

The color parameters $\left(L^{*}, a^{*}\right.$, and $\left.b^{*}\right)$ of fermented milk product with and without reuterin did not change significantly over the storage period. Likewise, Al Mijan et al. (2014) observed no drastic changes in the color parameters of yogurt stored at $5^{\circ} \mathrm{C}$ for $16 \mathrm{~d}$, although they did observe differences in $L^{*}, a^{*}$, and $b^{*}$ parameters between the yogurt with the antimicrobial agent and the control.

Fermented milk product without reuterin displayed higher $L^{*}$ values than fermented milk product with reuterin, but fermented milk product with reuterin tended to show higher $a^{*}$ and $b^{*}$ values than its reuterin-free counterpart, which would signify a shift from light greenish tones to yellowish-orange tones. However, simple visual inspection did not produce noteworthy color differences. Similarly, Gómez-Torres et al. (2014) studied the effect of $L b$. reuteri and glycerol addition to cheese milk for reuterin production, to avoid the growth of Clostridium tyrobutyricum. The authors observed 
Table 3. Rheological parameters of fermented milk product with and without reuterin during storage ${ }^{1,2}$

\begin{tabular}{|c|c|c|c|}
\hline Reuterin/storage (d) & $\mathrm{G}^{\prime}(\mathrm{Pa})$ & $\mathrm{G}^{\prime \prime}(\mathrm{Pa})$ & Viscosity $(\mathrm{Pa} \cdot \mathrm{s})$ \\
\hline \multicolumn{4}{|l|}{ With reuterin } \\
\hline 1 & $1.06 \pm 0.18$ & $1.26 \pm 0.62$ & $7.82 \times 10^{-7} \pm 2.07 \times 10^{-6}$ \\
\hline 7 & $0.68 \pm 0.05$ & $0.70 \pm 0.13$ & $3.06 \times 10^{-6} \pm 2.66 \times 10^{-6}$ \\
\hline 14 & $1.14 \pm 0.30$ & $1.90 \pm 1.20$ & $2.40 \times 10^{-6} \pm 1.38 \times 10^{-6}$ \\
\hline 21 & $1.08 \pm 0.17$ & $1.96 \pm 0.96$ & $4.81 \times 10^{-6} \pm 3.67 \times 10^{-6}$ \\
\hline 28 & $0.96 \pm 0.04$ & $0.41 \pm 0.52$ & $2.73 \times 10^{-6} \pm 1.94 \times 10^{-6}$ \\
\hline \multicolumn{4}{|l|}{ Without reuterin } \\
\hline 1 & $1.24 \pm 0.34$ & $1.53 \pm 0.93$ & $1.98 \times 10^{-6} \pm 1.21 \times 10^{-6}$ \\
\hline 7 & $1.00 \pm 0.18$ & $1.39 \pm 0.46$ & $4.61 \times 10^{-6} \pm 4.30 \times 10^{-6}$ \\
\hline 14 & $0.98 \pm 0.07$ & $0.99 \pm 0.28$ & $1.26 \times 10^{-6} \pm 2.04 \times 10^{-7}$ \\
\hline 21 & $0.91 \pm 0.03$ & $1.05 \pm 0.12$ & $1.28 \times 10^{-6} \pm 4.48 \times 10^{-6}$ \\
\hline 28 & $0.90 \pm 0.05$ & $0.89 \pm 0.21$ & $4.23 \times 10^{-6} \pm 4.75 \times 10^{-6}$ \\
\hline
\end{tabular}

${ }^{1}$ Values are the mean of 3 replicates \pm SD.

${ }^{2} \mathrm{G}^{\prime}=$ storage modulus; $\mathrm{G}^{\prime \prime}=$ loss modulus.

that cheeses made with the highest glycerol concentration $(100 \mathrm{~m} M)$ showed positive values for $a^{*}$, resulting in cheeses with a slight pink color. The authors associated this color difference to a reaction of reuterin or its derivatives with peptides or amino acids in the milk, forming colored compounds. Moreover, Montiel et al. (2016) reported that changes of color in cooked ham containing reuterin were due to high reuterin activity with sulfhydryl groups.

Soluble solids (mainly lactose) did not change throughout the refrigerated storage period. We observed small differences between reuterin-free and reuterin-rich fermented milk products, showing lower values in reuterin-free fermented milk products. Shelflife studies for yogurt typically indicate a decrease in soluble solids over the shelf life when live lactobacilli are present (Mataragas et al., 2011).

Table 3 shows the rheological parameters $\left(G^{\prime}, G^{\prime \prime}\right.$, and viscosity) of fermented milk product with and without reuterin during refrigerated storage. Reuterin presence in fermented milk product did not have a significant effect on rheology parameters. We observed average values of 0.995 and 1.208 for $G^{\prime}$ and $G^{\prime \prime}$, respectively. The predominance of $\mathrm{G}^{\prime \prime}$ over $\mathrm{G}^{\prime}$ indicates the tendency of the fermented milk product to behave more as a liquid than a solid. This behavior may have been due to the relatively high $\mathrm{pH}$ levels and stirring used in this study compared with set yogurts acidified to lower levels (Özer and Kirmaci, 2010).

\section{CONCLUSIONS}

Reuterin was an effective antimicrobial agent for the preservation of fermented milk product. All studied microorganisms were inactivated under study conditions. One of the most resistant microorganisms was Lb. reuteri ATCC 53608 suspended in glycerol water solutions, and the most sensitive was E. coli $\mathrm{DH} 5 \alpha$. On the other hand, $P$. expansum was the most sensitive to reuterin in the fermented milk product. We observed higher reuterin susceptibility in gram-negative than in gram-positive microorganisms. Although some changes to $\mathrm{pH}$, acidity, soluble solids, and color were caused by reuterin in fermented milk product, these changes did not adversely affect quality. Quality parameters did not vary over the shelf life for fermented milk products with or without reuterin. Reuterin could be an adequate alternative for the preservation of fermented milk products.

\section{ACKNOWLEDGMENTS}

The authors thank Verónica González-Vigil and Ángel Esparza-Chávez for their technical assistance. This research was supported by the Mexican National Council of Science and Technology (CONACYT).

\section{REFERENCES}

Al Mijan, M., K.-H. Choi, and H.-S. Kwak. 2014. Physicochemical, microbial, and sensory properties of nanopowdered eggshell-supplemented yogurt during storage. J. Dairy Sci. 97:3273-3280.

FAO (Food and Agriculture Organization of the United Nations). 2011. Codex Alimentarius: Milk and Milk Products. 2nd ed. Food and Agriculture Organization of the United Nations, World Health Organization, Rome, Italy.

AOAC International. 2002. Official Methods of Analysis. 17th ed. AOAC International, Gaithersburg, MD.

Arqués, J. L., J. Fernández, P. Gaya, M. Nuñez, E. Rodríguez, and M. Medina. 2004. Antimicrobial activity of reuterin in combination with nisin against food-borne pathogens. Int. J. Food Microbiol. 95:225-229.

Arqués, J. L., E. Rodríguez, M. Nuñez, and M. Medina. 2007. Inactivation of Gram-negative pathogens in refrigerated milk by reuterin in combination with nisin or the lactoperoxidase system. Eur. Food Res. Technol. 227:77-82.

Axelsson, L. T., T. C. Chung, W. J. Dobrogosz, and S. E. Lindgren. 1989. Production of a broad spectrum antimicrobial substance by Lactobacillus reuteri. Microb. Ecol. Health Dis. 2:131-136.

Bauer, R., M. du Toit, and J. Kossmann. 2010. Influence of environmental parameters on production of the acrolein precursor 3-hydroxypropionaldehyde by Lactobacillus reuteri DSMZ 20016 
and its accumulation by wine lactobacilli. Int. J. Food Microbiol. $137: 28-31$.

Bianchi, D. M., F. Ingravalle, D. Adriano, S. Gallina, M. Gramaglia, F. Zuccon, S. Astegiano, A. Bellio, G. Macori, G. Ru, and L. Decastelli. 2014. Reproducibility study for the detection of staphylococcal enterotoxins in dairy products between official Italian national laboratories. J. Food Prot. 77:999-1004.

Birollo, G. A., J. A. Reinheimer, and C. G. Vinderola. 2000. Viability of lactic acid microflora in different types of yoghurt. Food Res. Int. 33:799-805.

Braden, C. R., and R. V. Tauxe. 2013. Emerging trends in foodborne diseases. Infect. Dis. Clin. North Am. 27:517-533.

Chung, T. C., L. Axelsson, S. E. Lindgren, and W. J. Dobrogosz. 1989. In vitro studies on reuterin synthesis by Lactobacillus reuteri. Microb. Ecol. Health Dis. 2:137-144.

Circle, S. J., L. Stone, and C. S. Boruff. 1945. Acrolein determination by means of tryptophan: A colorimetric micromethod. Ind. Eng. Chem. 17:259-262.

Cleusix, V., C. Lacroix, S. Vollenweider, M. Duboux, and G. Le Blay. 2007. Inhibitory activity spectrum of reuterin produced by Lactobacillus reuteri against intestinal bacteria. BMC Microbiol. 7:101.

Cruz, A. G., R. N. Cavalcanti, L. M. R. Guerreiro, A. S. Sant'Ana, L. C. Nogueira, C. A. F. Oliveira, R. Deliza, R. L. Cunha, J. A. F. Faria, and H. M. A. Bolini. 2013. Developing a prebiotic yogurt: Rheological, physico-chemical and microbiological aspects and adequacy of survival analysis methodology. J. Food Eng. 114:323-330

Cruz, A. G., E. H. M. Walter, R. S. Cadena, J. A. F. Faria, H. M. A. Bolini, H. P. Pinheiro, and A. S. Sant'Ana. 2010. Survival analysis methodology to predict the shelf-life of probiotic flavored yogurt. Food Res. Int. 43:1444-1448.

Doleyres, Y., P. Beck, S. Vollenweider, and C. Lacroix. 2005. Production of 3-hydroxypropionaldehyde using a two-step process with Lactobacillus reuteri. Appl. Microbiol. Biotechnol. 68:467-474.

Donkor, O. N., S. L. I. Nilmini, P. Stolic, T. Vasiljevic, and N. P. Shah. 2007. Survival and activity of selected probiotic organisms in settype yoghurt during cold storage. Int. Dairy J. 17:657-665.

El-Sharoud, W. M. 2009. Prevalence and survival of Campylobacter in Egyptian dairy products. Food Res. Int. 42:622-626.

el-Ziney, M. G., and J. M. Debevere. 1998. The effect of reuterin on Listeria monocytogenes and Escherichia coli O157:H7 in milk and cottage cheese. J. Food Prot. 61:1275-1280.

Garde, S., N. Gómez-Torres, M. Hernández, and M. Ávila. 2014. Susceptibility of Clostridium perfringens to antimicrobials produced by lactic acid bacteria: Reuterin and nisin. Food Contr. 44:22-25.

Gómez-Torres, N., M. Ávila, P. Gaya, and S. Garde. 2014. Prevention of late blowing defect by reuterin produced in cheese by a Lactobacillus reuteri adjunct. Food Microbiol. 42:82-88.

Gonzalez, N. J., K. Adhikari, and M. F. Sancho-Madriz. 2011. Sensory characteristics of peach-flavored yogurt drinks containing prebiotics and synbiotics. LWT Food Sci. Technol. (Campinas) 44:158-163.

Gulmez, M., and A. Guven. 2003. Survival of Escherichia coli O157:H7, Listeria monocytogenes $4 \mathrm{~b}$ and Yersinia enterocolitica 03 in different yogurt and kefir combinations as prefermentation contaminant. J. Appl. Microbiol. 95:631-636.

Gyawali, R., and S. A. Ibrahim. 2014. Natural products as antimicrobial agents. Food Contr. 46:412-429. https://doi.org/10.1016/j. foodcont.2014.05.047.

Hekmat, S., H. Soltani, and G. Reid. 2009. Growth and survival of Lactobacillus reuteri $\mathrm{RC}-14$ and Lactobacillus rhamnosus GR-1 in yogurt for use as a functional food. Innov. Food Sci. Emerg. Technol. 10:293-296.

Helander, I. M., A. von Wright, and T.-M. Mattila-Sandholm. 1997. Potential of lactic acid bacteria and novel antimicrobials against Gram-negative bacteria. Trends Food Sci. Technol. 8:146-150.
Kemal, J. 2014. A review on the public health importance of bovine salmonellosis. J. Vet. Sci. Technol. 5:175.

Langa, S., J. M. Landete, I. Martín-Cabrejas, E. Rodríguez, J. L. Arqués, and M. Medina. 2013. In situ reuterin production by Lactobacillus reuteri in dairy products. Food Contr. 33:200-206.

Lüthi-Peng, Q., F. B. Dileme, and Z. Puhan. 2002a. Effect of glucose on glycerol bioconversion by Lactobacillus reuteri. Appl. Microbiol. Biotechnol. 59:289-296.

Lüthi-Peng, Q., S. Schärer, and Z. Puhan. 2002b. Production and stability of 3-hydroxypropionaldehyde in Lactobacillus reuteri. Appl. Microbiol. Biotechnol. 60:73-80.

Mataragas, M., V. Dimitriou, P. N. Skandamis, and E. H. Drosinos. 2011. Quantifying the spoilage and shelf-life of yoghurt with fruits. Food Microbiol. 28:611-616.

Mills, S., C. Stanton, C. Hill, and R. P. Ross. 2011. New developments and applications of bacteriocins and peptides in foods. Annu. Rev. Food Sci. Technol. 2:299-329.

Montiel, R., I. Martín-Cabrejas, A. Peirotén, and M. Medina. 2016. Reuterin, lactoperoxidase, lactoferrin and high hydrostatic pressure treatments on the characteristics of cooked ham. Innov. Food Sci. Emerg. Technol. 35:111-118.

Morgan, D., C. P. Newman, D. N. Hutchinson, A. M. Walker, B Rowe, and F. Majid. 1993. Verotoxin producing Escherichia coli O157 infections associated with the consumption of yoghurt. Epidemiol. Infect. 111:181-187.

Mroueh, M., D. Issa, J. Khawand, B. Haraty, A. Malek, Z. Kassaify, and I. Toufeili. 2008. Levels of benzoic and sorbic acid preservatives in commercially produced yoghurt in Lebanon. J. Food Agric. Environ. 6:62-66.

O'Mahony, M., E. Mitchell, R. J. Gilbert, D. N. Hutchinson, N. T. Begg, J. C. Rodhouse, and J. E. Morris. 1990. An outbreak of foodborne botulism associated with contaminated hazelnut yoghurt. Epidemiol. Infect. 104:389-395.

Özer, B. H., and H. A. Kirmaci. 2010. Quality attributes of yogurt and functional dairy products. Pages 229-265 in Development and Manufacture of Yogurt and Other Functional Dairy Products. F. Yildiz, ed. Taylor \& Francis Group, Boca Raton, FL.

Rasch, M. 2002. The influence of temperature, salt and $\mathrm{pH}$ on the inhibitory effect of reuterin on Escherichia coli. Int. J. Food Microbiol. 72:225-231.

Spinler, J. K., M. Taweechotipatr, C. L. Rognerud, C. N. Ou, S. Tumwasorn, and J. Versalovic. 2008. Human-derived probiotic Lactobacillus reuteri demonstrate antimicrobial activities targeting diverse enteric bacterial pathogens. Anaerobe 14:166-171.

Talarico, T. L., I. A. Casas, T. C. Chung, and W. J. Dobrogosz. 1988 Production and isolation of reuterin, a growth inhibitor produced by Lactobacillus reuteri. Antimicrob. Agents Chemother. 32:18541858

Talarico, T. L., and W. J. Dobrogosz. 1989. Chemical characterization of an antimicrobial substance produced by Lactobacillus reuteri. Antimicrob. Agents Chemother. 33:674-679.

Tobajas, M., A. F. Mohedano, J. A. Casas, and J. J. Rodríguez. 2007 A kinetic study of reuterin production by Lactobacillus reuteri PRO 137 in resting cells. Biochem. Eng. J. 35:218-225.

Vollenweider, S., G. Grassi, I. König, and Z. Puhan. 2003. Purification and structural characterization of 3-hydroxypropionaldehyde and its derivatives. J. Agric. Food Chem. 51:3287-3293.

Vollenweider, S., and C. Lacroix. 2004. 3-Hydroxypropionaldehyde: Applications and perspectives of biotechnological production. Appl. Microbiol. Biotechnol. 64:16-27.

Yildiz, F. 2010. Overview of yogurt and other fermented dairy products. Pages 1-45 in Development and Manufacture of Yogurt and Other Functional Dairy Products. F. Yildiz, ed. Taylor \& Francis Group, Boca Raton, FL. 